\title{
AKTIVITAS DAN JARINGAN KERJA PEMBUATAN KAPAL PERIKANAN 5 GT DI GALANGAN KAPAL UD. OLIONG KABUPATEN ROKAN HILIR PROVINSI RIAU
}

\section{ACTIVITY AND NETWORK OF BUILDING FISHING VESSEL 5 GT IN UD. OLIONG SHIPYARD ROKAN HILIR REGENCY RIAU PROVINCE}

\author{
Muhammad Natsir Kholis ${ }^{*}$, Suci Asrina Ikhsan², Ulley Wulandari³ \\ 1 Universitas Muaro Bungo, Jambi, Indonesia \\ 2Politeknik Kelautan dan Perikanan Dumai, Dumai, Indonesia \\ ${ }^{3}$ Politeknik Kelautan dan Perikanan Karawang, Karawang, Indonesia \\ * Korespondensi: kholis2336@gmail.com (MN Kholis) \\ Diterima 4 Maret 2020 - Disetujui 25 Maret 2020
}

\begin{abstract}
ABSTRAK. Memproduksi kapal perikanan yang tepat sesuai dengan tujuan tangkapan merupakan salah satu kemajuan bidang perikanan, kunci utamanya manajemen yang baik. Pengusaha galangan kapal harus bisa mengalokasikan waktu seefektif dan seefisien mungkin. Hal itu bertujuan untuk meningkatkan produksi hasil tangkapan ikan. Tujuan penelitian ini yaitu untuk melihat aktivitas pembangunan kapal perikanan di UD. Oliong dan mengalisis jaringan kerja proses pembangunannya. Metode yang digunakan yaitu metode survei. Penelitian dilaksanakan pada bulan November-Desember 2017 di UD. Oliong Bagansiapi-api Kecamatan Bangko Kabupaten Rokan Hilir Provinsi Riau. Hasil penelitian menunjukkan bahwa terdapat dua aktivitas galangan kapal UD.Oliong yaitu docking dan pembangunan kapal. Sedangkan jalur kritis jaringan kerja pembangunan kapal 5 GT di galangan kapal UD.Oliong yaitu aktivitas pada kode $A, B, C, E, F, H, I, J$ dan $K$, dengan waktu penyelesaian efektif 22 hari kerja.
\end{abstract}

KATA KUNCI: Galangan kapal perikanan; jaringan kerja; Bagansiapi-api; Riau

ABSTRACT. Producing the right fishing vessel in accordance with the catching goals is one of the advances in the field of fisheries, the main key is good management. Shipyard entrepreneurs must be able to allocate time as effectively and efficiently as possible. It aims to increase fish catch production. The purpose of this study is to look at fishing vessel building activities at UD. Oliong and analyzing the network process. The method used is the survey method. The study was conducted in November - December 2017 at UD. Oliong Bagansiapi-api Bangko District, Rokan Hilir Regency, Riau Province. The results showed that there were two UD.Oliong shipyard activities, namely docking and ship building. Whereas the critical path of the $5 \mathrm{GT}$ shipbuilding network in the UD. Oliong shipyard is activity code $A, B, C, E, F, H, I, J$ and $K$, with an effective completion time of 22 working days.

KEYWORDS: Fishing shipyard; network; Bagansiapi-api; Riau

\section{Pendahuluan}

Kabupaten Rokan Hilir merupakan wilayah yang didominasi oleh perairan laut, dimana sebagian besar dari perairan tersebut merupakan bagian teritorial Selat Malaka. Berdasarkan letak geografis dan kondisi perairan, Kabupaten Rokan Hilir merupakan daerah yang potensial penghasil ikan. Dimana terdapat 4 Kecamatan yang merupakan daerah pesisir yang potensial dalam perikanan tangkap yaitu Kecamatan Bangko, Sinaboi, Kubu dan Pasir Limau Kapas. 
Salah satu kemajuan bidang perikanan yaitu menghasilkan kapal perikanan yang tepat sesuai dengan tujuan tangkapannya, kunci utama kemajuan tersebut berawal dari manajemen yang baik. Pengusaha pembuat kapal (galangan kapal perikanan) harus bisa mengalokasikan waktu seefektif dan seefisien mungkin. Hal itu bertujuan untuk meningkatkan produksi hasil tangkapan ikan. Galangan kapal (dock) adalah tempat dimana segala kegiatan yang menyangkut reparasi kapal yang rusak, perawatan kapal dan proses pembangunan kapal dilaksanakan (Ahmad, 2004). Galangan kapal perikanan memiliki perbedaan dengan galangan kapal lainnya yaitu kekhususannya untuk membangun dan membuat kapal yang digunakan dalam usaha perikanan, teristimewa kapal penangkapan ikan.

Pada saat ini terdapat sekitar 240 perusahaan galangan dalam negeri yang tersebar di Indonesia, 37\% berada di pulau Jawa, 26\% di Sumatra, 25\% di Kalimantan dan 12\% berada di kawasan timur Indonesia, dengan kapasitas pembangunan kapal terpasang sebesar 140.000 GT per tahun. Namun demikian rata-rata produksi kapal per tahun sebesar 85.000 GT sedangkan rata-rata reparasi kapal baru mencapai 65.000 GT per tahun. Padahal sebenarnya potensi pasar galangan kapal dalam negeri sangatlah besar. Hal ini salah satunya dapat dilihat dari tingginya kebutuhan angkutan perdagangan internasional dan antar pulau belum lagi kapal penangkap ikan yang mencapai volume 400 juta ton per tahun. Sayangnya, hanya 18,08\% yang menggunakan kapal berbendera Indonesia. $\mathrm{Hal}$ ini terjadi karena ketidakmampuan perusahaan pelayaran nasional untuk membeli armada kapal dari galangan kapal dalam negeri (Windyandari, 2008).

Industri galangan kapal di Indonesia saat ini menjadi prioritas utama pemerintah berkaitan dengan program poros maritim yang sedang dijalankan. Berkaitan dengan hal tersebut pembangunan galangan yang sesuai serta efisien dan efektif menjadi tantangan dari para pelaku industri maritim (Saputra et al., 2017). Usaha galangan kapal yang terdata di Dinas Perindustrian dan Perdagangan Kabupaten Rokan Hilir (2014) berjumlah 20 unit kelompok usaha yang penyerapan tenaga kerja perunit kapal berkisar antara 2 sampai 18 orang tergantung pada ukuran kapal yang dibuat. Kapasitas produksi kapal kayu di Rokan Hilir adalah 1 sampai 25 unit pertahun berdasarkan skala usaha dan kekuatan modal usaha. Hal ini juga tergantung dari jumlah pesanan dan ketersediaan bahan baku.

Usaha galangan kapal kayu tradisional di Kabupaten Rokan Hilir dikelola secara perorangan dan bersifat usaha rumahan (home industry), salah satunya UD. Oliong. Tujuan penelitian ini yaitu untuk melihat aktivitas pembangunan kapal perikanan di UD. Oliong dan mengalisis jaringan kerja proses pembangunannya.

\section{Bahan dan Metode}

\subsection{Lokasi dan Waktu Penelitian}

Lokasi penelitian yaitu di UD. Oliong Bagansiapi-api Kecamatan Bangko Kabupaten Rokan Hilir Provinsi Riau. Survei dilakukan sebanyak 10 kali yaitu pada bulan November-Desember 2017. Lokasi penelitian dapat dilihat pada Gambar 1.

\subsection{Jenis dan Pengambilan Data}

Penelitian ini dilaksanakan dengan menggunakan metode survei, dengan mengamati dan turun langsung ke lapangan melihat aktifitas galangan kapal kayu perikanan UD. Oliong di Bagansiapi-api Kecamatan Bangko Kabupaten Rokan Hilir Provinsi Riau. Teknik pengambilan data menggunakan teknik wawancara berupa urutan proses pembangunan kapal perikanan serta waktu pengerjaannya. Sumber data utama yaitu data primer dan data sekunder sebagai data tambahan. Bahan sekaligus objek pada penelitian ini yaitu kapal perikanan yang dibangun UD. Oliong Bagansiapi-api Kecamatan Bangko Kabupaten Rokan Hilir Provinsi Riau. Sedangkan alat yang digunakan yaitu: alat tulis, kuisioner, jangka sorong, meteran, kamera digital dan alat pendukung lainnya. 


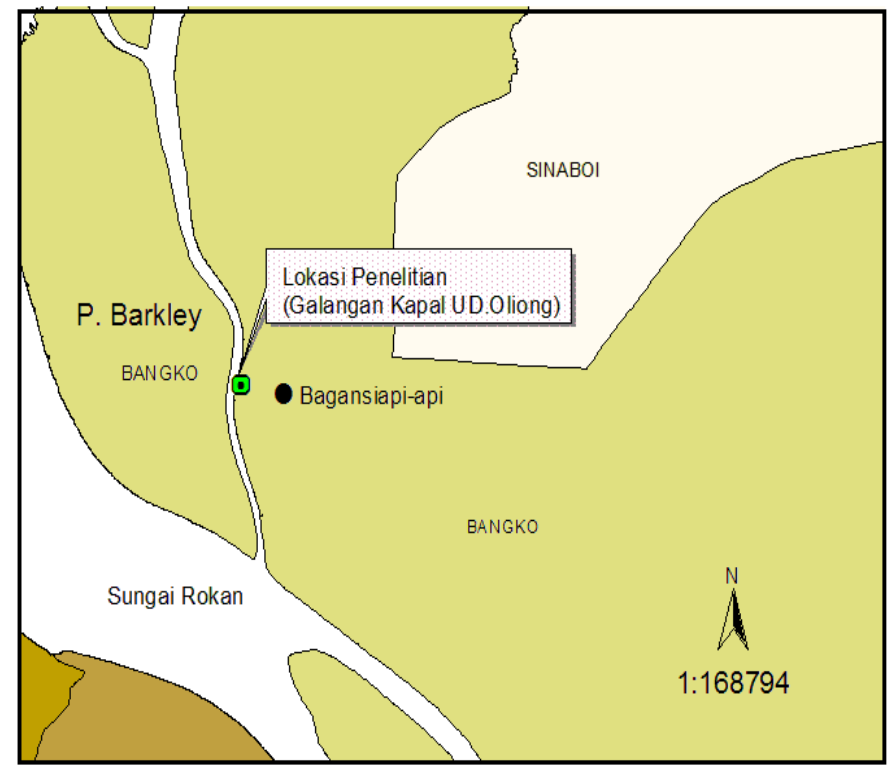

PETA LOKASI PENELITIAN

By. Muhammad Natsir Kholis Universitas Muara Bungo

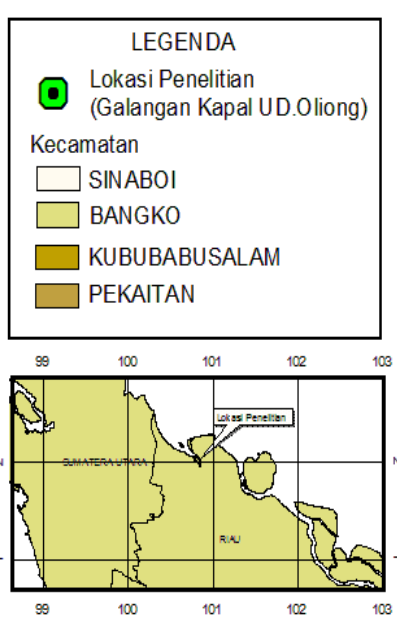

Gambar 1. Lokasi Penelitian di UD. Oliong Bagansiapi-api Kecamatan Bangko Kabupaten Rokan Hilir Provinsi Riau

\subsection{Analisis Data}

Data aktivitas galangan kapal perikanan di UD. Oliong dianalisis secara deskriptif. Sedangkan data jaringan kerja dianalisis dengan Critical Path Method (CPM) (Shankar et al., 2010). Secara keseluruhan lama waktu setiap kegiatan dapat digabungkan dengan asumsi-asumsi sebagai berikut:

1. Jumlah pelaku adalah sama, 6 orang;

2. Kapal berukuran $5 \mathrm{GT}$;

3. Kapal yang dibuat beralasan sama, $V$ bottom;

4. Kondisi alam dianggap sama,yaitu musim kemarau; dan

5. Semua pelaku kegiatan memiliki kemampuan yang sama.

\section{Hasil dan Pembahasan}

\subsection{Keadaan Umum Lokasi Penelitian}

Kecamatan Bangko mempunyai luas $475,26 \mathrm{~km}^{2}$ atau sekitar 5,35 persen dari total wilayah Kabupaten Rokan Hilir Bagansiapi-api. Ibu Kota kecamatan Bangko terletak di Kota Bagansiapi-api pada koordinat 209'28,08"LU dan 100048'58,68"BT. Kota Bagansiapi-api dijuluki sebagai Hong Kong van Andalas dan dahulunya merupakan kota penghasil ikan terbesar setelah kota Bergen, Norwegia pada tahun 1928. Kota Bagansiapi-api Kecamatan Bangko juga dilewati Sungai Rokan yang panjangnya sekitar $350 \mathrm{~km}$ dan berbatasan langsung dengan Selat Malaka. Kondisi ini sangat berguna bagi masyarakat baik sebagai tempat mata pencaharian menangkap ikan maupun sebagai sarana transportasi.

Kapasitas produksi kapal kayu di Kabupaten Rokan Hilir adalah 1 sampai 25 unit pertahun berdasarkan skala usaha dan kekuatan modal usaha. Hal ini juga tergantung dari jumlah pesanan dan ketersediaan bahan baku. Gambaran usaha galangan kapal kayu dan kapasitanya menurut kelompok industri dapat dilihat pada Tabel 1. Salah satu galangan kapal yang ada di Kabupaten Rokan Hilir yaitu galangan kapal UD. Oliong. Galangan kapal ini memiliki beberapa fasilitas untuk menunjang aktivitas pembangunan kapal seperti: dock, gudang material (tempat penyimpanan sementara material atau komponen yang dibutuhkan galangan kapal), tempat pengolahan kayu, rumah penginapan pekerja galangan dan lahan parkir 
Tabel 1. Kelompok Industri Kapal Kayu dan Perahu di Kabupaten Rokan Hilir

\begin{tabular}{clccc} 
No & \multicolumn{1}{c}{ Nama Perusahaan } & Bentuk Badan Usaha & Jenis Kapal & $\begin{array}{c}\text { Tenaga Keja } \\
\text { (Orang) }\end{array}$ \\
\hline $\mathbf{1}$ & Dock Kapal Asuan & Perorangan & Kapal Kayu & 9 \\
$\mathbf{2}$ & Dock Acai & Perorangan & Kapal Kayu & 15 \\
$\mathbf{3}$ & Dock Sapeng & Perorangan & Kapal Kayu & 8 \\
$\mathbf{4}$ & UD. Oliong & Perorangan & Kapal Kayu & 10 \\
$\mathbf{5}$ & Dock Nolek & Perorangan & Kapal Kayu & 8 \\
$\mathbf{6}$ & Dock Alian & Perorangan & Kapal Kayu & 9 \\
$\mathbf{7}$ & Dock Kapal Obak & Perorangan & Kapal Kayu & 10 \\
$\mathbf{8}$ & Dock Giling & Perorangan & Kapal Kayu & 5 \\
$\mathbf{9}$ & Dock Singkok & Perorangan & Kapal Kayu & 15 \\
$\mathbf{1 0}$ & Dock Gi Hwan & Perorangan & Kapal Kayu & 18 \\
$\mathbf{1 1}$ & Dock Aseng & Perorangan & Kapal Kayu & 2 \\
$\mathbf{1 2}$ & Dock Awi Kwanla & Perorangan & Kapal Kayu & 2 \\
$\mathbf{1 3}$ & Dock Kapal Gui Sin Se & Perorangan & Kapal Kayu & 2 \\
$\mathbf{1 4}$ & Dock Kapal Ahu & Perorangan & Kapal Kayu & 1 \\
$\mathbf{1 5}$ & Dock Cok Tan & Perorangan & Kapal Kayu & 1 \\
16 & Usaha Sampan Zainal & Perorangan & Kapal Kayu & 5 \\
$\mathbf{1 7}$ & Usaha Kapal Sinar & Perorangan & Kapal Kayu & 4 \\
$\mathbf{1 8}$ & Dock Kapal Cipta & Perorangan & Kapal Kayu & 2 \\
19 & Dock Kapal Ahok & Perorangan & Kapal Kayu & 2 \\
$\mathbf{2 0}$ & Dock Kapal Alan & Perorangan & Kapal Kayu & 2 \\
\hline
\end{tabular}

Usaha Produktivitas galangan kapal kayu tradisional di Bagansiapi-api dikelola secara perorangan dan bersifat usaha rumahan. Secara umum keadaan pengelolaan galangan kapal kayu tradisional di Bagansiapi-api masih sederhana, dapat dikategorikan berskala kecil, tidak memiliki Surat Izin Usaha (SIU). Selain itu galangan kapal kayu tradisional tersebut tidak berupa perusahaan yang merupakan badan hukum dalam bentuk PT ataupun CV. Hal itu dengan mudah dijumpai dari penamaan galangan kapal tersebut hanya berdasarkan nama pemilik galangan kapal. Data produksi kapal dalam tiga tahun terakhir di UD. Oliong dapat dilihat pada (Tabel 2.).

Tabel 2. Produktivitas Galangan Kapal UD. Oliong Dari Tahun 2013 - 2015

\begin{tabular}{ccccc}
\hline \multirow{2}{*}{ No } & Ukuran Kapal & \multicolumn{3}{c}{ Tahun } \\
\cline { 3 - 5 } & & $\mathbf{2 0 1 3}$ & $\mathbf{2 0 1 4}$ & $\mathbf{2 0 1 5}$ \\
\hline 1 & $<50 \mathrm{GT}$ & 2 & 1 & 1 \\
2 & $50-150 \mathrm{GT}$ & 1 & 2 & 2 \\
3 & $150-350 \mathrm{GT}$ & 1 & - & 1 \\
\hline
\end{tabular}

\subsection{Aktivitas Galangan Kapal UD. Oliong}

\subsubsection{Docking}

Docking merupakan landasan di tepi laut atau perairan sungai yang digunakan untuk membangun/merakit kapal dan mengangkat kapal yang akan diperbaiki/pemeliharaan jika mengalami kerusakan. Umumnya landasan tersebut miring kearah permukaan air dan memanjang sampai kebawah permukaan air yang dimaksudkan untuk meluncurkan kapal ke air setelah selesai dibangun atau perbaikan.

Menurut Apriliani et al., (2014) kegiatan perbaikan kapal yang dilakukan di galangan kapal KPNDP terbagi menjadi 3 jenis pemeliharaan yaitu: pemeliharaan tahunan (perbaikan kapal ringan), 
dok besar (perbaikan kapal berat) dan pemeliharaan berat. Selain itu menurut Nurwanti et a.l, (2016) perbaikan kapal (reparasi) pada umumnya menyangkut 3 hal yaitu: badan kapal, permesinan kapal dan outfitting.

Beberapa persyaratan utama suatu lokasi dapat membuat dock kapal ialah:

1) Lahan dekat dengan perairan, sehingga mudah untuk mengangkut bahan baku dan mudah menurunkan kapal.

2) Terlindungi dari sinar matahari, Lahan galangan tersebut harus berada di antara pohon-pohon yang rindang sehingga para pekerja terlindungi dari sengatan matahari secara langsung.

3) Kontur lahan relatif datar, Karena dalam pembuatan kapal posisi lunas dipersyaratkan untuk berada pada posisi lurus dan datar.

4) Lahan galangan selalu dalam keadaan kering, Sehingga memudahkan pekerja bekerja memasang bagian-bagian dari bangunan kapal.

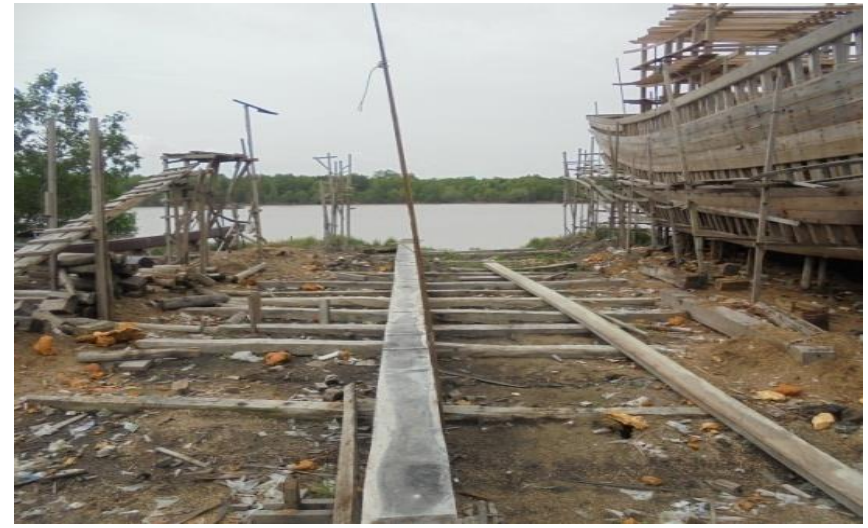

Gambar 2. Aktivitas Docking Kapal

\subsubsection{Teknologi Pembangunan Kapal}

Teknologi pembangunan kapal dilihat berdasarkan tingkat teknologinya, pembangunan kapal di galangan UD. Oliong masih relatif rendah. Pembangunan kapal hanya berdasarkan pengalaman turun temurun dan kebiasaan para pengrajin. Pada umumnya galangan kapal membuat kapal tanpa disertai dengan gambar rancangan detail. Pembuatan kapal hanya dilengkapi dengan gambar sketsa kapal yang akan dibangun. Akan tetapi, galangan tersebut juga dapat menerima pesanan pembuatan kapal yang telah dilengkapi dengan gambar detail seperti general arrangement dan profile construction yang berasal dari pihak pemesan. Biasanya pemesan kapal yang dilengkapi dengan gambar detail dan perhitungan arsitek perkapalan berasal dari dinas-dinas pemerintahan atau pihak asing.

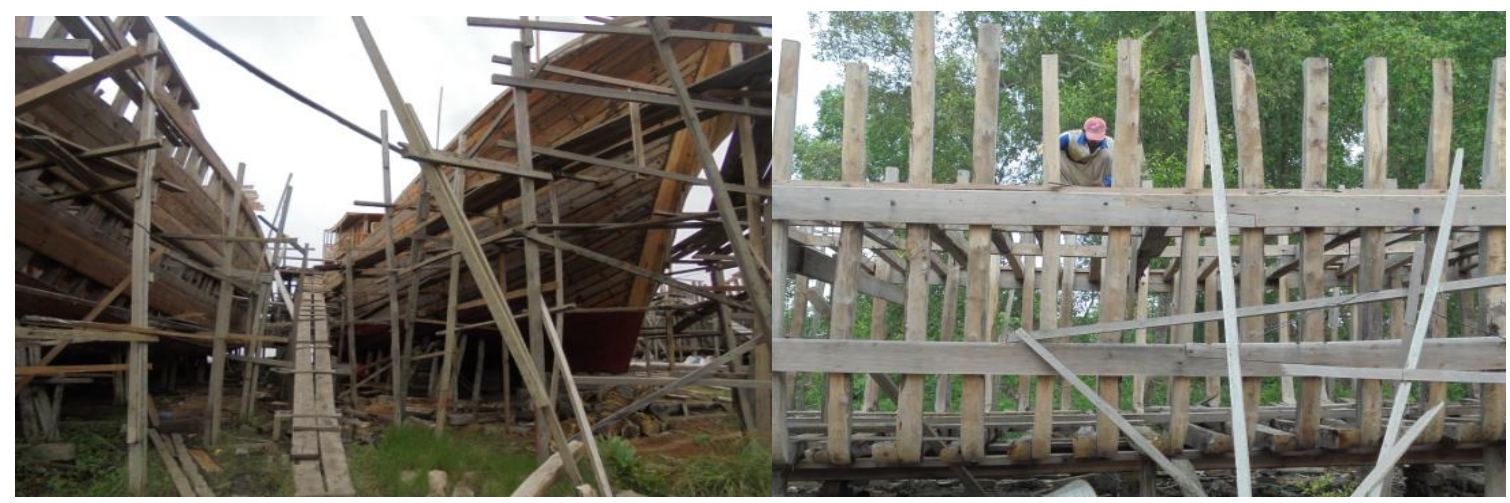

Gambar 3. Aktivitas Pembangunan Kapal 
Peralatan yang digunakan untuk membuat kapal juga masih sederhana dan didominasi oleh peralatan non elektronik. Hal ini dikarenakan galangan kapal masih tradisional dan penggunaan peralatan tersebut sudah merupakan kebiasaan turun-temurun. Hasil observasi dilapangan, jarang sekali ditemukan alat-alat modern berupa alat-alat elektronik yang mampu memberikan kemudahan bagi para pengrajin kapal dalam proses pengerjaan pembangunan kapal. Meskipun demikian, kapal yang diproduksi di daerah ini sudah terbukti kemampuan dan kekuatannya. Beberapa peralatan yang digunakan di galangan kapal yang ada di Bagansiapi-api dapat dilihat pada Tabel 3.

Tabel 3. Peralatan yang digunakan Galangan Kapal UD. Oliong

\begin{tabular}{clcc} 
No & \multicolumn{1}{c}{$\begin{array}{c}\text { Peralatan Yang Digunakan } \\
\text { Galangan Kapal }\end{array}$} & $\begin{array}{c}\text { Jenis Peralatan } \\
\text { Elektronik/Non Elektronik }\end{array}$ & $\begin{array}{c}\text { Jumlah Yang } \\
\text { Digunakan }\end{array}$ \\
\hline 1 & Kapak & Non elektronik & 4 \\
2 & Gergaji & Non elektronik & 3 \\
3 & Pahat & Non elektronik & 4 \\
4 & Catok & Non elektronik & 3 \\
5 & Pasak & Non elektronik & 3 \\
6 & Palu & Non elektronik & 5 \\
7 & Mal besi & Non elektronik & 3 \\
8 & Golok & Non elektronik & 5 \\
9 & Alat ukur & Non elektronik & 4 \\
10 & Obeng & Non elektronik & 3 \\
11 & Mesin Singso & Non elektronik & 3 \\
12 & Linggis & Non elektronik & 2 \\
13 & Bor listrik & Elektronik & 3 \\
14 & Ketam listrik & Elektronik & 3 \\
\hline
\end{tabular}

\subsubsection{Kontruksi Kapal 5 GT}

Menurut Ayodhyoa (1972), menyatakan bahwa karakteristik kapal perikanan berbeda dengan kapal jenis lainnya sehingga memiliki beberapa keistimewaan antara lain: kecepatan kapal (speed), kemampuan olah gerak kapal, Layak laut (seaworthiness), luas lingkup area pelayaran, konstruksi, mesin penggerak, fasilitas penyimpanan dan pengolahan ikan dan alat bantu penangkapan (fishing equipment).

Ukuran kapal yang dibangun galangan kapal UD Oliong sangat bervariasi, berkisar antara 3 350 GT. Hasil wawancara menunjukkan bahwa ukuran kapal yang dominan dibuat saat ini yaitu ukuran kapal 5 GT, dengan spesifikasi panjang (LOA) 12 meter dan tinggi breadth 2,3 meter. Ukuran 5 GT sangat sering dipesan karena harganya sangat terjangkau oleh masyarakat nelayan. Alat tangkap yang digunakan nelayan dengan kapal 5 GT yaitu jaring insang (gillnet) permukaan dan dasar, ada juga pancing serta rawai. Menurut Kholis et al., (2019) ukuran kapal gillnet di PPI Muara Angke berkisar antara 8 - 30 GT. Sedangkan menurut Pasaribu et al., (2011) ukuran kapal gillnet di PPN Sungailiat Bangka Belitung yaitu 5 -8 GT, dengan LOA 2,7 meter, Lpp 3,38 meter, breadth 1,2 meter , depth 0,72 meter dan draft 0,18 meter.

Pulau Tidung memiliki ukuran kapal gillnet 5 GT dengan LOA 13,7 meter, Lpp 10,34 meter, breadth 2,8 meter, depth 1,08 meter dan draft 0,54 meter. Perbedaan ukuran tidak menjadi masalah untuk kecepatan, kekuatan, maupun kestabilan kapal jika dibuat dengan standar rasio (Pasaribu et al., 2011). Pasaribu et al., (2011) juga menjelaskan desain kapal bottom gillnet untuk body plan yaitu round flat bottom dan round bottom, untuk profile plan bagian buritan tepatnya pada bagian propeller melengkung menuju ke lunas dan half breadht plan mengikuti body plan. Karakteristik desain kapal 
bottom gillnet dimensi utamanya telah memenuhi kriteria standar rasio dimensi utama kapal. Kontruksi bentuk badan kapal adalah $V$ bottom pada bagian haluan dan $U$ pada bagian tengah kapal. Bahan yang digunakan dalam pembuatan kapal adalah kayu meranti dan kayu ulin. Ditambahkan Iskandar (1990) untuk kapal gillnet agar dapat beroperasi dengan lincah maka diperlukan nilai Lpp (L) yang besar, breadth (B) yang sedang dan depth (D) yang kecil karena ketiga nilai ini dimensi utama kapal. Kontruksi kapal 5 GT yang dibangun galangan kapal UD.Oliong dapat dilihat pada (Gambar 4).

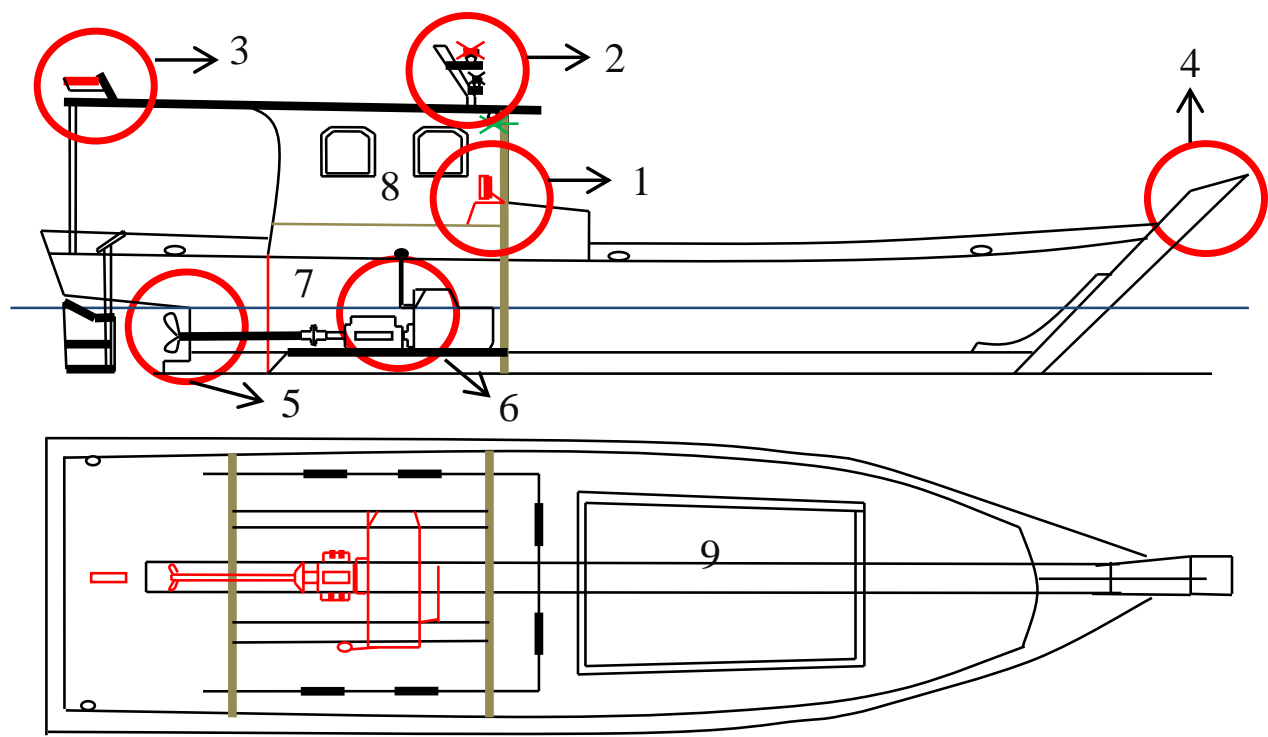

Keterangan:
1. Kemudi
6. Mesin
2. Lampu Navigasi
7. Kamar Mesin
3. Bendera
8. Ruang Kemudi
4. Linggi
9. Ruang Palkah
5. Propeller

\section{Gambar 4. Kontruksi Kapal 5 GT yang dibangun Galangan Kapal UD.Oliong}

\subsection{Analisis Jaringan Kerja Pembangunan Kapal 5 GT di Galangan Kapal UD. Oliong}

Proses pembangunan kapal perikanan 5 GT di galangan kapal UD. Oliong diawali dengan penentuan dimensi dan sketsa kapal yang akan dibuat oleh pemilik galangan. Dimensi dan sketsa kapal tersebut dapat berasal dari dua sumber, yaitu dari pihak pemesan dan pemilik galangan itu sendiri. Jika dari pihak pemesan disertai dengan gambar general arrangement, lines plan, deck profile, dan profile construction, maka pemilik galangan membuat kapal berdasarkan gambar detail tersebut. Tetapi jika tidak disertai dengan gambar detail, maka pemilik galangan yang akan menentukan dimensi dan sketsanya. Setelah itu dilakukan pemilihan material atau balok-balok kayu berkualitas sesuai dengan bagian-bagian kapal yang akan dibangun. Hal ini dilakukan karena masing-masing bagian kapal dibangun dari jenis kayu yang berbeda. Penggunaan kayu untuk konstruksi kapal di suatu tempat bergantung pada kebiasaan pengrajin kapal di tempat tersebut. Menurut Iskandar \& Novita (2000) pembangunan kapal perikanan tradisional dengan bahan kayu di Indonesia cukup bervariasi, baik dari segi tahapan pembangunan, teknik penyambungan tiap bagian-bagian konstruksi yang dilakukan maupun tingkat teknologi pembangunannya.

Setelah tahap persiapan selesai dilakukan, maka proses pembangunan kapal segera dilakukan. Pembangunan kapal dimulai dengan peletakan lunas dan pemasangan linggi. Kemudian dilanjutkan dengan pemasangan gading-gading, hingga pemasangan kulit lambung kapal bagian bawah terlebih 
dahulu lalu pemasangan kerangka utama lambung bagian atas. Setelah itu, dilanjutkan lagi dengan pembuatan dek dan palkah. Tahap akhir dari proses pembangunan kapal 5 GT adalah pengecatan, pemasangan mesin, propeller dan kemudi. Proses pembangunan kapal di UD. Oliong sesuai dengan pendapat Pasaribu (1985), bahwa tahapan pembangunan kapal dimulai dari pemasangan lunas, linggi haluan dan buritan, gading-gading, balok geladak, galar, kulit luar dan geladak. Sedangkan bagianbagian lainnya dapat dikerjakan secara bersamaan atau bagian yang satu dapat dikerjakan lebih dahulu dari pada bagian yang lain Secara berurutan tahapan pembangunan kapal di galangan kapal UD. Oliong dapat dilihat pada (Tabel 4.).

Tabel 4. Tahapan dan Waktu Pembangunan Kapal 5 GT di Galangan Kapal UD. Oliong

\begin{tabular}{|c|c|c|c|c|}
\hline Nomor & Kode & Aktivitas & $\begin{array}{c}\text { Kegiatan } \\
\text { Pendahuluan }\end{array}$ & $\begin{array}{l}\text { Waktu } \\
\text { (hari) }\end{array}$ \\
\hline 1 & A & Peletakan lunas & - & 1 \\
\hline 2 & B & Pemasangan linggi & $A$ & 2 \\
\hline 3 & C & Pemasangan gading-gading & $A$ & 4 \\
\hline 4 & $\mathrm{D}$ & $\begin{array}{l}\text { Pemasangan kulit lambung kapal bagian } \\
\text { bawah }\end{array}$ & C & 2 \\
\hline 5 & $E$ & $\begin{array}{l}\text { Pemasangan kulit lambung/dinding bagian } \\
\text { atas }\end{array}$ & C & 3 \\
\hline 6 & $\mathrm{~F}$ & Pembuatan dek & $E$ & 3 \\
\hline 7 & G & Pembuatan palka & D & 2 \\
\hline 8 & $\mathrm{H}$ & Pembuatan bangunan diatas kapal (geladak) & $F, G$ & 3 \\
\hline 9 & I & Ruang dalam kapal & $\mathrm{H}$ & 2 \\
\hline 10 & $\mathrm{~J}$ & $\begin{array}{l}\text { Pengamplasan dan penambalan lubang } \\
\text { (pemakalan) }\end{array}$ & I & 2 \\
\hline 11 & $\mathrm{~K}$ & Pengecatan & I & 2 \\
\hline 12 & L & $\begin{array}{l}\text { Pemasangan mesin, propeller dan kemudi } \\
\text { (finishing) }\end{array}$ & $\mathrm{J}$ & 4 \\
\hline
\end{tabular}

Tabel 4 menunjukkan tahapan kegiatan pembangunan dan kegiatan yang mendahului serta waktu yang dibutuhkan dalam pembangunan kapal 5 GT di galangan kapal UD.Oliong. Setiap kegiatan mempunyai pendahuluan kecuali aktivitas peletakkan lunas. Kegiatan yang memiliki pendahuluan lebih dari 1 yaitu aktivitas pembuatan bangunan diatas kapal (geladak) yang memiliki 2 pendahulu. Aktivitas pemasangan gading-gading dan finishing (pemasangan mesin, propeller dan kemudi) yang memiliki waktu terlama yaitu 4 hari kerja.

Tahapan proses pembangunan kapal 5 GT di galangan kapal UD Oliong digambarkan ke dalam diagram jaringan kerja yang ditunjukkan (Gambar 5). Shankar et al., (2010) menyatakan bahwa sebuah jaringan kerja didefinisikan sebagai serangkaian kegiatan yang harus dilakukan dalam menjalankan proyek. Jaringan kerja tersebut dapat direpresentasikan oleh diagram jaringan kerja untuk mengarahkan suatu proyek agar berjalan sesuai yang diharapkan.

Istilah penting dalam jaringan kerja yaitu slack, slack merupakan perbedaan waktu, sehingga memungkinkan adanya sejumlah tenaga kerja yang menganggur. Kegiatan yang memiliki nilai slack 0 (nol) merupakan kegiatan yang berada pada jalur kritis. Jalur kritis ditunjukkan apabila suatu kegiatan tidak memiliki perbedaan waktu atau kelonggaran waktu (slack) pada sebuah rangkaian kegiatan (Stelth \& Roy 2009). Ada 9 aktivitas pembangunan kapal 5 GT di galangan UD.Oliong yang mengalami slack yaitu aktivitas pada kode A, B, C, E, F, H, I, J dan K. Kegiatan yang mengalami slack merupakan jalur kritis pembangunan kapal 5 GT di galangan UD.Oliong. Jalur kritis tersebut perlu diprioritaskan agar tidak terjadi keterlambatan, seperti aktivitas peletakan lunas, pemasangan linggi, pemasangan kulit lambung kapal bagian bawah, dan lainnya. Masalah yang sering terjadi dalam pembangunan kapal 
5 GT di galangan UD.Oliong adalah keterbatasan teknologi dan keterbatasan tenaga kerja. Pada Gambar $\mathbf{5}$ dapat dilihat bahwa diagram jaringan kerja sebagian besar memiliki pola mendatar lurus dan sangat minim bercabang, hal itu menunjukkan pembangunan kapal di UD.Oliong masih sangat sederhana dan tergolong kategori tradisional.

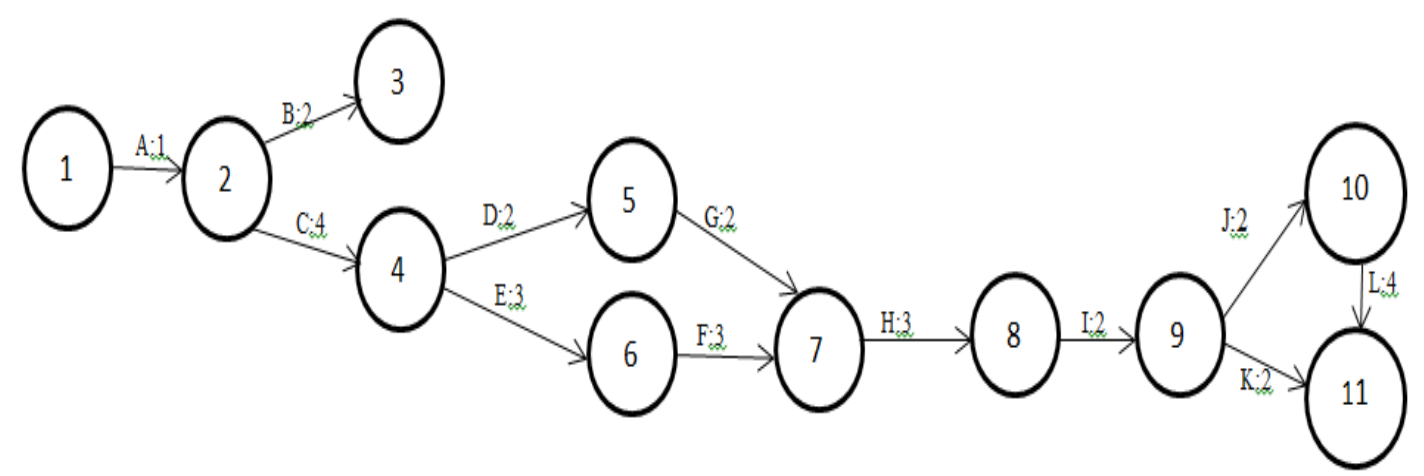

Gambar 5. Diagram jaringan kerja pembangunan kapal 5 GT di Galangan Kapal UD.Oliong

Gambar 6 menunjukkan waktu penyelesaian atau jalur lintasan pembangunan kapal 5 GT di galangan UD.Oliong yaitu memiliki waktu penyelesaian efektif: $1+2+4+3+3+3+2+2+2=22$ hari, dari waktu prakiraan selesai pembangunan selama 30 hari. Susanto et al., (2006) menyebutkan bahwa kegiatan produksi harus diarahkan untuk menjamin terdapatnya kontinuitas dan koordinasi kegiatan dalam usaha pengelolaan dan penyelesaian hasil produksi yang sesuai dengan bentuk, kuantitas, kualitas dan waktu yang diinginkan. Sedangkan menurut Apriliani et al., (2014) faktor yang mempengaruhi pembangunan kapal diantaranya yaitu situasi dan kondisi lapangan, cuaca yang mempengaruhi kinerja pembangunan/perbaikan kapal, sumberdaya yang dimiliki oleh pihak galangan seperti tenaga kerja, kemampuan dan keterampilan tenaga kerjanya.

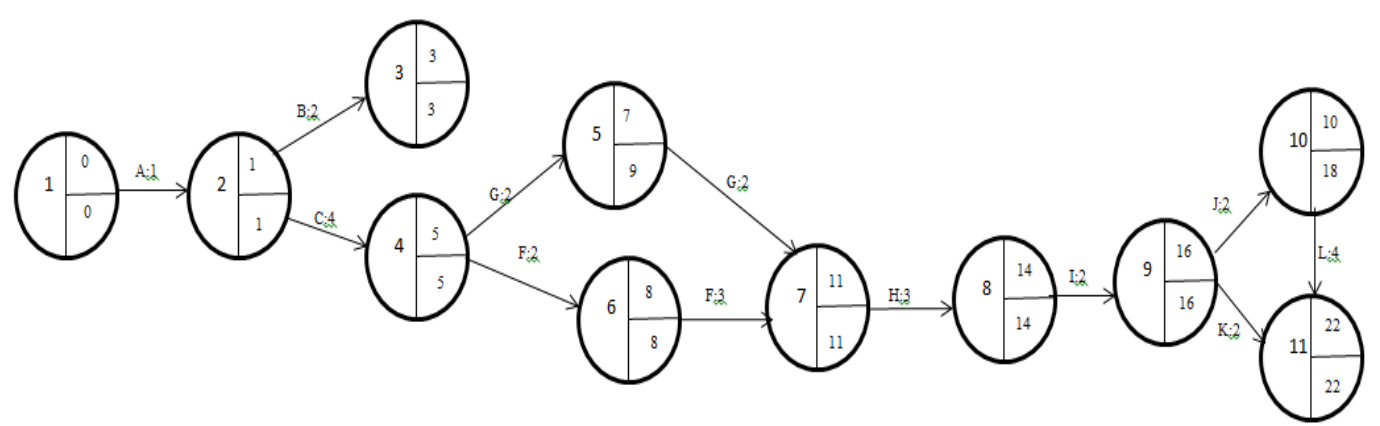

\section{Gambar 6. Diagram Waktu Lintasan Proyek dan Jalur Kritis Pembangunan Kapal 5 GT di Galangan Kapal UD.Oliong}

Dilihat dari waktu kerja, galangan kapal UD.Oliong sudah menerapkan jangka waktu kerja sesuai peraturan pemerintah yaitu 8 - 10 jam/hari. Apabila ada proyek pembangunan kapal dalam jumlah banyak maka pekerja dan pemilik galangan akan berdiskusi untuk menetapkan jam kerja lembur bagi para pekerjanya, sesuai anggaran yang telah disepakati bersama.

Jam kerja bagi para pekerja di sektor swasta diatur dalam Undang-Undang No. 13 tahun 2003 tentang Ketenagakerjaan pasal 77 - 85. Pasal 77 ayat 1 UU No. 13/2003 mewajibkan setiap pengusaha melaksanakan ketentuan jam kerja, yaitu 8 jam kerja dalam 1 hari untuk 5 hari kerja dengan waktu kerja sekurang-kurangnya setengah jam setelah bekerja selama 4 jam terus menerus yang dijelaskan pada UU 13/2003 pasal 79, sehingga waktu kerja efektif adalah 7 jam per hari. 


\section{Kesimpulan}

Kesimpulan yang didapatkan dari hasil analisis bahwa aktivitas galangan kapal UD.Oliong yaitu docking dan pembangunan kapal. Sedangkan jalur krtitis jaringan kerja pembangunan kapal 5 GT di galangan kapal UD.Oliong yaitu aktivitas pada kode $A, B, C, E, F, H, I, J$ dan $K$, dengan waktu penyelesaian efektif 22 hari kerja.

\section{Daftar Pustaka}

Ahmad M. (2004). Pengelolaan Galangan Kapal Skala Menengah di Dumai. Jurnal IImu Administrasi Pasca Sarjana Universitas Riau, 2(2), 120-128.

Apriliani IM., Wisudo SH., Iskandar BH., \& Novita, Y. (2014). Jaringan Kerja dan Efektivitas Perbaikan

Kapal di Galangan KPNDP DKI Jakarta, Muara Angke. Marine Fisheries, 5(1), 79-89.

Ayodhyoa AU. (1972). Craft and Gear. Jakarta (ID): Correspondence Course Centre. 66 hal.

Dinas Perindustrian dan Perdagangan Kabupaten Rokan Hilir. (2014). Laporan Statistik Usaha Masyarakat Kecil dan Menengah Kabupaten Rokan Hilir, Provinsi Riau.

Iskandar BH. (1990). Studi tentang desain dan kontruksi Kapal Gillnet di Indramayu. [Skripsi]. Bogor:

Fakultas Perikanan dan IImu Kelautan, Institut Pertanian Bogor.

Iskandar., BH \& Novita., Y. (2000). Tingkat Teknologi Pembangunan Kapal Ikan Kayu Tradisional di Indonesia. Jurnal Buletin PSP, 9(20): 53-67.

Kholis MN., Jaya MM., Hutapea RY., Bangun TNC., \& Hehanussa, KG. (2018). Karakteristik Alat Tangkap Jaring Insang (Gill Net) di Pangkalan Pendaratan Ikan (PPI) Muara Angke Jakarta Utara. SEMAH Jurnal Pengelolaan Sumberdaya Perairan, 2(2).

Nurwanti R., \& Pribadi, TW. (2016). Analisa Peningkatan Kualitas Layanan Jasa Reparasi Kapal di Galangan Kapal Jawa Timur. Jurnal Teknik ITS, 5(1), 41-46.

Pasaribu R., Fauziyah., \& Agustriani, F. (2011). Karakteristik Desain Kapal Perikanan Bottom Gillnet di Pelabuhan Perikanan Nusantara (PPN) Sungailiat, Bangka Belitung. Maspari Journal, 2, 54-62.

Pasaribu, BP. (1985). Keadaan Umum Kapal Ikan di Indonesia. Prosiding Seminar Kapal Ikan di Indonesia dalam Rangka Implementasi Wawasan Nusantara. Institut Pertanian Bogor. 106 hal.

Saputra B., Mulyatno IP., \& Amiruddin, W. (2017). Studi Perancangan Galangan Kapal untuk Pembangunan Kapal Baru dan Perbaikan di Area Pelabuhan Pekalongan. Jurnal Teknik Perkapalan, 5(2), 353-366.

Shankar NR., Sireesha V., Rao KS., \& Vani, N. (2010). Fuzzy Critical Path Method on Metric Distance Ranking of Fuzzy Numbers. International Jurnal of Math Analysis. 4(20), 995-1006.

Stelth P., \& Roy GL. (2009). Projects' Analysis through CPM (Critical Path Method). School of Doctoral Studies (European Union) Jurnal. (1), 10-51.

Susanto N., Purwaningsih R., \& Ardiansyah E. (2006). Analisis Jaringan Kerja dan Penentuan Jalur Kritis dengan Critical Path Method-CPM. JTI Undip. (1), 74-84.

Undang-Undang Republik Indonesia Nomor 13 Tahun 2003 tentang Ketenagakerjaan. Hukumonline.com [Diunduh 23 November 2019].

Windyandari A. (2008). Prospek Industri Galangan Kapal dalam Negeri Guna Menghadapi Persaingan Global. Jurnal Teknik, 29 (1), 73-77. 